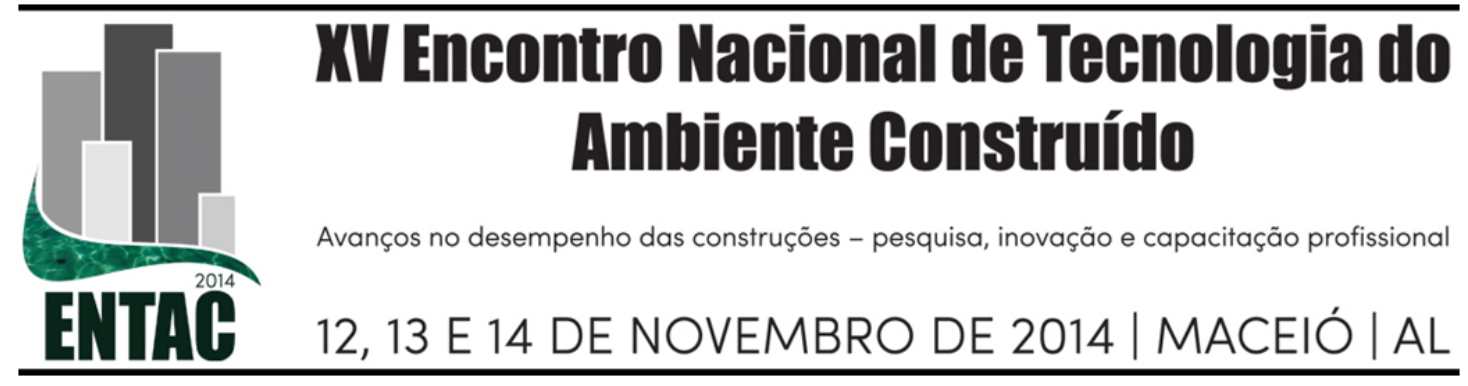

\title{
PROPOSTA DE INDICADORES DE DESEMPENHO PARA UMA EMPRESA DE CONSULTORIA NA GESTÃO DA CONSTRUÇÃO
}

\author{
SANTOS, Rúbia Bernadete Pereira dos (1); PALADINI, Edson Pacheco (2); \\ JUNGLES, Antônio Edésio (3)
}

(1) UFSC, (47) 9676-4948, e-mail: rubiabpds@gmail.com (2) UFSC, e-mail: paladini@deps.ufsc.br, (3) UFSC, e-mail: ajungles@ceped-ufsc.br

\begin{abstract}
RESUMO
A sobrevivência de uma organização depende de sua capacidade de avaliação do ambiente interno e externo, e de sua aptidão em transformar os objetivos estratégicos em ações. Ciente desta afirmação, este artigo propõe a elaboração de indicadores de desempenho, por meio do modelo Balanced Scorecard (BSC), aplicado a um estudo de caso, em uma empresa consultora em gestão de obras na construção civil. A organização foi fundada no inicio de 2013, portanto, esta em processo de organização de seus processos gerenciais internos, por meio do qual a proposição de indicadores permitiria o acompanhamento da evolução de suas atividades. Para tanto, realizaram-se entrevistas semiestruturadas, com os representantes da empresa, durante o segundo trimestre do ano de 2013. Com base nas informações obtidas, foram elaborados vinte indicadores, sendo: nove no ambiente on line (caracterizado pela relação entre a organização e o mercado), cinco no off line (definido pelas atividades de suporte aos processos operacionais); cinco in line (ambiente onde são desenvolvidos os processos operacionais) e um misto no ambiente on e in line. Os indicadores refletem o atual estado da organização, permitindo a tomada de decisão para a melhoria contínua da empresa. Portanto, com uma abordagem proativa dos indicadores os processos são conduzidos para uma maior eficiência, evitando falhas e promovendo melhores resultados financeiros do negócio.
\end{abstract}

Palavras chave: Indicadores; Balanced Scorecard (BSC), gestão da construção.

\begin{abstract}
The survival of an organization depends of its capacity to evaluate the external and internal environment, and of its ability to transform strategic objectives in actions. Aware of this, this paper proposes the implementation of performance indicators, through Balanced Scorecard (BSC) model, applied in a case study in a consulting company in management of civil constructions. The organization was founded at the beginning of 2013, therefore, in this organization process their internal management processes, through which indicators are proposed to allow monitoring the evolution of its activities. In this regard, in the second quarter of 2013 were carried semi-structured interviews with the representatives of the company. Based in these information were created twenty indicators, as follows: nine in online environment (characterized by the relation between the company and the market), five in offline (defined by the support activities to the operating process), five in inline (environment where operating process are developed) and in a mixed environment on and in line. The indicators reflect the current state of the organization, enabling decision making for continuous improvement of the company. Therefore, with a proactive approach to indicators processes are driven to greater efficiency by avoiding failures and promoting better financial results of the business.
\end{abstract}

Keywords: Indicators; Balanced Scorecard (BSC); construction management. 


\section{INTRODUÇÃO}

A indústria da construção civil possui uma função estratégica no desenvolvimento econômico e social dos países, devido a sua representatividade no produto interno bruto e sua ação como geradora de empregos, onde em momentos de baixo crescimento econômico são fomentadas políticas públicas neste segmento econômico (KURESKI, 2011).

Contudo, apesar de sua importância, principalmente em países em desenvolvimento como o Brasil, as organizações deste segmento industrial são pouco consolidadas no que diz respeito ao desempenho dos processos gerenciais. De acordo com Dave e Koskela (2009), com a economia globalizada, a construção civil tem sofrido considerável pressão para melhorar o desempenho de seus processos produtivos.

Nesta conjuntura, um estudo realizado por Guzi (2011) a cerca da cultura organizacional das empresas do setor, relatou a carência no uso de ferramentas de controle dos processos gerenciais, bem como, ausência na elaboração de estratégias, dificuldades de comunicação, disseminação de objetivos e metas nas empresas de construção civil.

Em resposta à demanda e carência do mercado, no início da segunda década do século XXI, em uma capital sulina, foi criada uma empresa que presta consultoria em gestão de obras da construção civil, por meio de metodologias que integram o conhecimento científico e as vivências práticas.

Diante deste contexto, busca-se responder o seguinte problema de pesquisa: como avaliar o desempenho e a adequação das estratégias desta empresa consultora na gestão de obras da construção civil?

Para tanto, o presente estudo tem o intuito de elaborar os indicadores de desempenho a ser aplicados como ferramenta de controle e gestão em uma organização que presta consultoria em gestão da construção. Para atingir este objetivo geral, os seguintes objetivos específicos foram perseguidos: i) definir um modelo de avaliação de desempenho das organizações; ii) estudar as características da empresa selecionada para o estudo de caso; iii) elaborar a proposta de indicadores de desempenho.

A relevância deste artigo é caracterizada através das proposições apresentadas e da necessidade da organização em monitorar o desempenho da empresa e adequar os serviços prestados para garantir o diferencial competitivo e assegurar a sobrevivência no mercado.

Este artigo está organizado nas seguintes seções: 1 o capítulo introdutório; 2 o referencial teórico, contemplando os fundamentos teóricos sobre indicadores e o modelo BSC (Balanced Scorecard); 3 a metodologia utilizada; 4 o estudo de caso e os indicadores propostos; 5 as considerações finais e, por fim, as referências.

\section{REFERENCIAL TEÓRICO}

\subsection{Avaliação de Desempenho}

A avaliação do desempenho é essencial para as organizações, uma vez que determina o ambiente atual e impulsiona para a melhoria contínua da gestão da empresa. Contudo, Almahmoud, Doloi e Panuwatwanich (2012) alerta sobre a necessidade de modelos que forneçam uma abordagem proativa, de forma a conduzir os processos a melhores resultados e evitar falhas. 
De acordo com Azevedo (2009) a medição do desempenho se fundamenta nos indicadores, que são mecanismo de avaliação, com bases mensuráveis, de análise da qualidade e produtividade de uma organização, tornando o ambiente de decisões do negócio mais seguro e controlado, atraindo mais investimentos.

Contudo, estudos realizados na indústria da construção civil nacional descrevem que os indicadores de desempenho não são elaborados em consonância com os objetivos estratégicos da empresa, resultando em processos burocráticos ineficazes que não são incorporados aos processos gerenciais (HERNANDES, 2008; AZEVEDO, 2009).

Segundo Zorzi e Ensslin (2007), dentre os modelos de medição de desempenho, o Balanced Scorecard (BSC) é o mais utilizado para operacionalizar a estratégia da organização, pois clarifica a visão e a estratégia da organização traduzindo-as em planos de ação compreensíveis a todos os integrantes de uma organização.

Este sistema propõe a medição de indicadores financeiros e não financeiros, que analisam a sustentabilidade econômica do negócio, a satisfação dos clientes internos e externos, a qualidade dos serviços prestados, o sistema de aperfeiçoamento da organização e a capacidade da organização de se adaptar e mudar (GRIGOROUDIS;ORFANOUDAKI; ZOPOUNIDIS, 2012).

\subsection{Modelo BSC (Balanced Scorecard)}

O modelo Balanced Scorecard foi apresentado, na literatura científica, em 1992, por Robert Kaplan e Davis Norton, na Hardvard Business Review. O artigo tinha o intuito de apresentar um modelo de avaliação do desempenho, contudo, ficou reconhecido por desenvolver uma metodologia de gestão estratégica baseada em quatro perspectivas (KAPLAN; NORTON, 2000).

A combinação destas diferentes perspectivas por este sistema de medição e gestão, segundo Rajesh et al (2012), consente aos gestores uma visão holística do negócio, permitindo uma melhor compreensão das relações e das trocas entre as diferentes dimensões de desempenho, favorecendo a tomada de decisão e a resolução de problemas.

Segundo Kaplan e Norton (2000) o modelo Balanced Scorecard permite atingir este equilíbrio dinâmico entre os processos estratégico e as ações operacionais, utilizando quatro perspectivas distintas como estratégia para a criação de valor, sendo elas:

- financeira: atendimento do acionista, por meio de estratégias de crescimento, rentabilidade e risco;

- cliente: foco no cliente e na criação da imagem da empresa de diferenciação e criação de valor;

- processos e negócios internos: definição de prioridades estratégicas internas, de forma a satisfazer tanto os clientes quanto acionistas;

- aprendizado e crescimento: desenvolvimento de um ambiente organizacional propício à mudança, inovação e crescimento.

O conceito de Balanced Scorecard é muito relevante no ambiente atual, onde as organizações enfrentando clientes mais exigentes, concorrência mais intensa e legislações mais severas. Que alteraram o sistema de concorrência com base na capacidade de investir para um ambiente onde se valoriza o conhecimento e os ativos intangíveis como vantagem competitiva. (GHOSH; MUKHERJEE, 2006). 


\section{METODOLOGIA}

A presente pesquisa trata de um estudo de caso aplicado a uma organização que atua como consultora na gestão de obras da construção civil. Este estudo possui natureza qualitativa, com delineamento descritivo, ao delinear as características e procedimentos da empresa; e analítica, por avaliar e ponderar sobre os indicadores elaborados.

Inicialmente, foi realizada uma revisão bibliográfica, a respeito do tema "indicadores de desempenho". Nesta busca alçava-se determinar um modelo mais adequado para elaboração de indicadores, sendo definido o Balanced Scorecard (BSC) como o mais apropriado.

Por seguinte, para contextualizar a pesquisa, foi selecionada uma empresa consultora na área de gestão da construção, onde foi elaborado um estudo de caso, durante o segundo trimestre do ano de 2013. Com o intuito de elaborar o modelo, foram realizadas entrevistas semiestruturadas, com os representantes da empresa e estudada as informações disponíveis sobre a organização.

Conforme as recomendações de Kaplan e Norton (2000) as informações obtidas na organização, foram ordenadas de acordo com a o proposto pelo método em: visão estratégica da organização, objetivos estratégicos e fatores críticos de sucesso. $O$ vínculo com os indicadores foi realizado com base na definição dos fatores/medidas.

Após a definição dos fatores/medidas, foram utilizados os procedimentos propostos por Paladini (2011), para a elaboração dos indicadores. Por meio dos quais foram definidos: os objetivos, as justificativa, os padrões e os elementos de cada indicador. O método apresenta os indicadores agrupados em três ambientes: on, off e in line.

As definições e os indicadores foram validados pelos representantes da empresa, que acompanharam a elaboração dos indicadores e julgaram como adequados. Estes também atuaram como responsáveis pelas definições dos padrões admitidos como aceitáveis pela organização.

\section{ESTUDO DE CASO}

\subsection{Caracterização da empresa}

Em junho de 2012, em uma capital sulina, dois estudiosos da área de gestão da construção: um com vasto conhecimento das práticas de mercado e o segundo, com sólida experiência acadêmica. Observaram o contexto da construção civil e notaram uma lacuna a ser preenchida entre as pesquisas desenvolvidas nas instituições de ensino e as técnicas aplicadas nas construtoras de pequeno e médio porte, maioria no setor.

Estes estudiosos alinhavaram seus conhecimentos teóricos e as expectativas e demandas do mercado e elaboram um método que traduz as ferramentas e instrumentos científicos a uma linguagem acessível às práticas da construção civil. Desta forma, em março de 2013 instituíram uma empresa que presta consultoria às construtoras no desenvolvimento e personalização dos processos de gestão de obras.

A organização está fundamentada no aprimoramento dos processos de gestão da construção civil e valorização da praticidade e qualidade das ferramentas e técnicas, tendo como base a filosofia Lean Construction e o ciclo de melhoria contínua. Por meio de serviços de elaboração de orçamentos, planejamento e acompanhamento de obras, treinamentos in company, gestão ambiental no canteiro, entre outros. 
Em menos de seis meses a aceitação do mercado fez com que o quadro de funcionários fosse triplicado e continuassem em plena expansão. Atualmente, a empresa atende a várias construtoras, atuando em mais de vinte empreendimentos, distribuídos em várias cidades da região.

Para conquistar o mercado o foco esteve nas ações operacionais e foram abdicadas as ações táticas e estratégicas. Contudo, para cumprir a visão estratégica da organização, faz-se necessário a análise das ações de negócio com a intenção de manter as características de diferenciação pela aplicação prática do conhecimento técnico científico e promover o desempenho organizacional sustentável.

\subsection{Desenvolvimento dos indicadores de desempenho}

Os indicadores foram elaborados á partir da visão estratégica da organização, conforme recomendação da metodologia de Karplan e Norton (2000). Para tanto, a visão foi decomposta em objetivos estratégicos e em fatores críticos de sucesso, segundo as quatro perspectivas do modelo Balanced Scorecard (BSC), e definido o fator/medida descritos na Figura 01.

\section{Figura 01 - Resumo da aplicação do modelo Balanced Scorecard (BSC).}

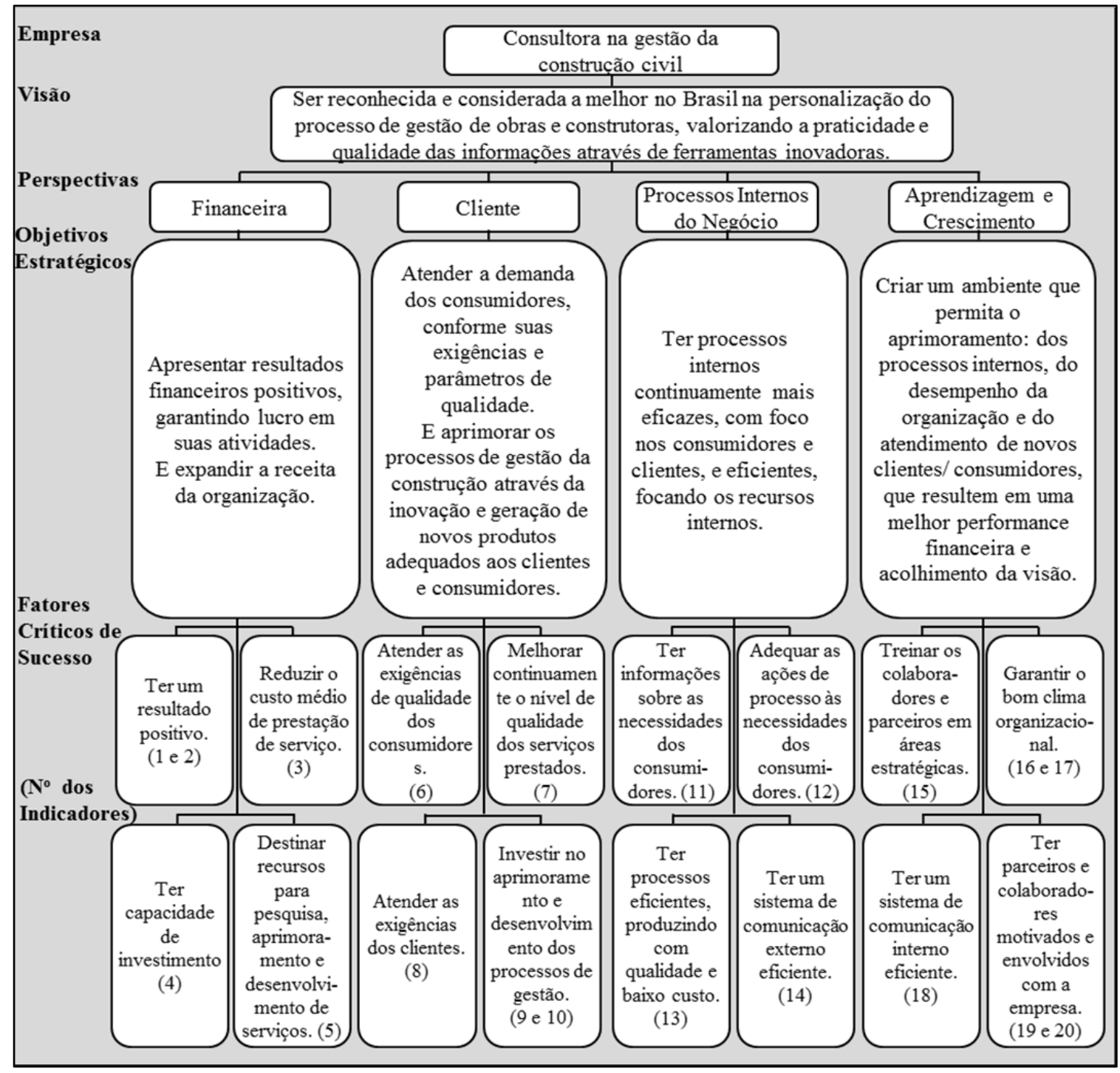


Por conseguinte, os fatores e medidas, foram utilizados como marco inicial na estruturação dos indicadores pelo método de Paladini (2011). Foram elaborados 20 indicadores, caracterizados como: 9 indicadores de ambiente on line (Quadro 01), 5 no ambiente off line (Quadro 02), 5 indicadores no ambiente in line (Quadro 03) e 1 no on e in line (Quadro 01 e Quadro 03).

Os indicadores do ambiente on line (Quadro 01) se caracterizam por avaliar as relações entre a organização e o mercado, deste modo, direcionando a organização para o atendimento do cliente. Sendo fator determinante à sobrevivência da empresa, devido a sua função de responder às mudanças no ambiente externo com velocidade e precisão das mutações (PALADINI, 2011).

\section{Quadro 01 - Indicadores ambiente on line.}

\begin{tabular}{|c|c|c|c|c|c|}
\hline $\begin{array}{l}\text { Indi- } \\
\text { cador }\end{array}$ & Objetivo & Justificativa & Padrão & Elemento & Fator/Medida \\
\hline 1 & $\begin{array}{l}\text { Analisar a } \\
\text { rentabilidade da } \\
\text { organização. }\end{array}$ & $\begin{array}{l}\text { Verificar se as ati- } \\
\text { vidades desenvol- } \\
\text { vidas apresentam } \\
\text { resultados positi- } \\
\text { vos à organização. }\end{array}$ & $\begin{array}{c}15 \% \text { do } \\
\text { faturamento }\end{array}$ & $\begin{array}{l}\text { Rentabilidade } \\
\text { da } \\
\text { organização. }\end{array}$ & $\begin{array}{l}\text { Percentual de } \\
\text { lucro líquido por } \\
\text { ano. }\end{array}$ \\
\hline 2 & $\begin{array}{l}\text { Avaliar o } \\
\text { crescimento da } \\
\text { organização. }\end{array}$ & $\begin{array}{c}\text { Conferir se as } \\
\text { atividades da } \\
\text { organização estão } \\
\text { conquistando a } \\
\text { fatia de atuação. }\end{array}$ & $5 \%$ ao ano & $\begin{array}{l}\text { Crescimento } \\
\text { da } \\
\text { organização. }\end{array}$ & $\begin{array}{l}\text { Percentual de } \\
\text { crescimento da } \\
\text { receita líquida por } \\
\text { ano. }\end{array}$ \\
\hline 5 & $\begin{array}{c}\text { Analisa a } \\
\text { adequação da } \\
\text { oferta de novos } \\
\text { serviços à } \\
\text { demanda do } \\
\text { mercado. } \\
\end{array}$ & $\begin{array}{c}\text { Verificar se os } \\
\text { novos serviços } \\
\text { oferecidos são } \\
\text { necessários e } \\
\text { adequados ao } \\
\text { mercado. } \\
\end{array}$ & $\begin{array}{l}20 \% \text { do } \\
\text { faturamento }\end{array}$ & $\begin{array}{l}\text { Aceitação do } \\
\text { mercado. }\end{array}$ & $\begin{array}{l}\text { Percentual de } \\
\text { faturamento com } \\
\text { novos serviços } \\
\text { por ano. }\end{array}$ \\
\hline 6 & $\begin{array}{l}\text { Determinar a } \\
\text { eficácia do } \\
\text { processo interno } \\
\text { em corresponder } \\
\text { às expectativas } \\
\text { consumidores. } \\
\end{array}$ & $\begin{array}{c}\text { Manter os } \\
\text { consumidores } \\
\text { satisfeitos e suas } \\
\text { exigências } \\
\text { atendidas. }\end{array}$ & $\begin{array}{l}\text { Zero de } \\
\text { ocorrência }\end{array}$ & $\begin{array}{l}\text { Atendimento } \\
\text { aos } \\
\text { consumidores. }\end{array}$ & $\begin{array}{l}\text { Número de } \\
\text { reclamações } \\
\text { recebidas por } \\
\text { trimestre. }\end{array}$ \\
\hline 7 & $\begin{array}{c}\text { Analisar a } \\
\text { imagem da } \\
\text { organização } \\
\text { perante seus } \\
\text { consumidores. } \\
\end{array}$ & $\begin{array}{c}\text { Garantir a } \\
\text { satisfação dos } \\
\text { consumidores e a } \\
\text { sobrevivência da } \\
\text { organização. }\end{array}$ & 9,0 & $\begin{array}{l}\text { Satisfação dos } \\
\text { consumidores. }\end{array}$ & $\begin{array}{l}\text { Média do índice } \\
\text { de satisfação dos } \\
\text { consumidores por } \\
\text { ano. }\end{array}$ \\
\hline 8 & $\begin{array}{c}\text { Avaliar a } \\
\text { adequação das } \\
\text { propostas } \\
\text { elaboradas pela } \\
\text { organização as } \\
\text { expectativas do } \\
\text { mercado. }\end{array}$ & $\begin{array}{c}\text { Verificar se as } \\
\text { propostas } \\
\text { elaboradas pela } \\
\text { organização estão } \\
\text { captando clientes } \\
\text { e estão adequadas } \\
\text { à demanda do } \\
\text { mercado. } \\
\end{array}$ & $\begin{array}{l}90 \% \text { das } \\
\text { propostas } \\
\text { aceitas/ } \\
\text { realizadas. }\end{array}$ & $\begin{array}{l}\text { Atendimento } \\
\text { à } \mathrm{s} \\
\text { necessidades } \\
\text { dos clientes }\end{array}$ & $\begin{array}{l}\text { Percentual de } \\
\text { propostas } \\
\text { aprovadas pelos } \\
\text { clientes por } \\
\text { trimestre. }\end{array}$ \\
\hline
\end{tabular}


Continuação Quadro 01.

\begin{tabular}{|c|c|c|c|c|c|}
\hline $\begin{array}{l}\text { Indi- } \\
\text { cador }\end{array}$ & Objetivo & Justificativa & Padrão & Elemento & Fator/Medida \\
\hline 9 & $\begin{array}{l}\text { Determinar se a } \\
\text { organização tem } \\
\text { captado novos } \\
\text { consumidores. }\end{array}$ & $\begin{array}{l}\text { Avaliar o } \\
\text { crescimento } \\
\text { vertical da } \\
\text { organização, } \\
\text { captação de } \\
\text { clientes. }\end{array}$ & $\begin{array}{l}10,0 \text { novos } \\
\text { consumido- } \\
\text { res. }\end{array}$ & $\begin{array}{c}\text { Captação de } \\
\text { consumidores. }\end{array}$ & $\begin{array}{c}\text { Número de novos } \\
\text { consumidores por } \\
\text { ano. }\end{array}$ \\
\hline 10 & $\begin{array}{l}\text { Analisar se a } \\
\text { organização tem } \\
\text { aumentado } \\
\text { verticalmente. }\end{array}$ & $\begin{array}{c}\text { Avaliar o } \\
\text { crescimento } \\
\text { vertical da } \\
\text { organização. }\end{array}$ & $\begin{array}{l}5,0 \text { novos } \\
\text { consumido- } \\
\text { res/saída. }\end{array}$ & $\begin{array}{l}\text { Crescimento } \\
\text { da } \\
\text { organização. }\end{array}$ & $\begin{array}{c}\text { Número de } \\
\text { entrada/saída de } \\
\text { consumidores por } \\
\text { ano. }\end{array}$ \\
\hline 11 & $\begin{array}{c}\text { Determinar se as } \\
\text { novas } \\
\text { necessidades dos } \\
\text { consumidores têm } \\
\text { sido supridas pela } \\
\text { organização. }\end{array}$ & $\begin{array}{c}\text { Avaliar a } \\
\text { evolução dos } \\
\text { produtos de } \\
\text { acordo com as } \\
\text { expectativas dos } \\
\text { consumidores. }\end{array}$ & $\begin{array}{c}100 \% \text { das } \\
\text { sugestões/ } \\
\text { solicitações } \\
\text { atendidas. }\end{array}$ & $\begin{array}{l}\text { Evolução da } \\
\text { organização. }\end{array}$ & $\begin{array}{l}\mathrm{N}^{0} \text { de produtos } \\
\text { oferecidos a partir } \\
\text { de sugestões dos } \\
\text { consumidores por } \\
\text { ano. }\end{array}$ \\
\hline 12 & $\begin{array}{c}\text { Avaliar o } \\
\text { alinhamento dos } \\
\text { processos internos } \\
\text { as expectativas } \\
\text { dos } \\
\text { consumidores. }\end{array}$ & $\begin{array}{l}\text { Verificar a } \\
\text { eficácia dos } \\
\text { processos } \\
\text { internos. }\end{array}$ & $\begin{array}{c}\text { Zero de } \\
\text { ocorrência. }\end{array}$ & $\begin{array}{c}\text { Eficácia } \\
\text { organização. }\end{array}$ & $\begin{array}{l}\text { Número de } \\
\text { revisões por } \\
\text { produtos por } \\
\text { trimestre. }\end{array}$ \\
\hline
\end{tabular}

O ambiente on line, foi o que recebeu maior atenção, por ser responsável em atender os investidores, consumidores e clientes. Os indicadores 1 e 2 , referem-se às expectativas dos acionistas e necessidade de todas as organizações de fornecer lucro e crescer financeiramente. A pretensão dos indicadores $6,7,8$ e 12 é sobre a necessidade de corresponder às expectativas atuais, enquanto que, os indicadores 5, 9, 10 e 11 aspiram ao constante crescimento e adaptabilidade da empresa.

Segundo Paladini (2011) o ambiente off line, apresentado na Quadro 02, fornece a avaliação das atividades que dão suporte ao processo produtivo, sendo definidas basicamente como as ações de desenvolvimento dos recursos humanos, que atuam indiretamente na produção. Afinal, os colaboradores são os clientes internos e sua satisfação e qualidade reflete em todos os produtos e serviços oferecidos.

\section{Quadro 02 - Indicadores ambiente off line.}

\begin{tabular}{|c|c|c|c|c|c|}
\hline $\begin{array}{c}\text { Indi- } \\
\text { cador }\end{array}$ & Objetivo & Justificativa & Padrão & Elemento & Fator/Medida \\
\hline \multirow{1}{*}{16} & $\begin{array}{c}\text { Determinar o } \\
\text { envolvimento e } \\
\text { participação dos } \\
\text { colaboradores nos } \\
\text { eventos da } \\
\text { organização. }\end{array}$ & $\begin{array}{c}\text { Ampliar o } \\
\text { envolvimento nos } \\
\text { eventos da } \\
\text { organização. }\end{array}$ & $\begin{array}{c}\text { Em média } \\
90 \% \text { de } \\
\text { presença } \\
\text { dos colabo- } \\
\text { radores nos } \\
\text { eventos }\end{array}$ & $\begin{array}{c}\text { Envolvimento } \\
\text { dos } \\
\text { colaboradores }\end{array}$ & $\begin{array}{c}\text { Percentual de } \\
\text { colaboradores } \\
\text { presentes em } \\
\text { eventos da } \\
\text { organização } \\
\text { por trimestre. }\end{array}$ \\
\hline
\end{tabular}


Continuação Quadro 02.

\begin{tabular}{|c|c|c|c|c|c|}
\hline $\begin{array}{l}\text { Indi- } \\
\text { cador }\end{array}$ & Objetivo & Justificativa & Padrão & Elemento & Fator/Medida \\
\hline 17 & $\begin{array}{c}\text { Avaliar a } \\
\text { satisfação dos } \\
\text { colaboradores } \\
\text { com o ambiente. }\end{array}$ & $\begin{array}{l}\text { Melhorar as } \\
\text { características do } \\
\text { ambiente confor- } \\
\text { me expectativa } \\
\text { dos } \\
\text { colaboradores. }\end{array}$ & Média 9,0 & $\begin{array}{l}\text { Satisfação } \\
\text { equipe. }\end{array}$ & $\begin{array}{c}\text { Média do } \\
\text { índice de } \\
\text { avaliação do } \\
\text { ambiente } \\
\text { pelos } \\
\text { colaboradores } \\
\text { por trimestre. }\end{array}$ \\
\hline 18 & $\begin{array}{c}\text { Verificar o } \\
\text { comprometimento } \\
\text { da alta direção em } \\
\text { investir na quali- } \\
\text { ficação de seus } \\
\text { colaboradores. }\end{array}$ & $\begin{array}{l}\text { Capacitar os } \\
\text { colaboradores. }\end{array}$ & $\begin{array}{c}0,5 \% \text { do } \\
\text { faturamento } \\
\text { anual. }\end{array}$ & $\begin{array}{l}\text { Treinamento } \\
\text { dos } \\
\text { colaboradores. }\end{array}$ & $\begin{array}{l}\text { \% de inves- } \\
\text { timento apli- } \\
\text { cado em trei- } \\
\text { namento dos } \\
\text { colaboradores } \\
\text { por ano. }\end{array}$ \\
\hline 19 & $\begin{array}{l}\text { Analisar se os } \\
\text { fornecedores se } \\
\text { adequam às } \\
\text { necessidades da } \\
\text { organização. } \\
\end{array}$ & $\begin{array}{l}\text { Avaliar o } \\
\text { desempenho dos } \\
\text { fornecedores. }\end{array}$ & Média 9,0. & $\begin{array}{l}\text { Capacitação } \\
\text { dos } \\
\text { fornecedores }\end{array}$ & $\begin{array}{c}\text { Média do } \\
\text { índice de } \\
\text { avaliação dos } \\
\text { fornecedores } \\
\text { por ano. } \\
\end{array}$ \\
\hline 20 & $\begin{array}{c}\text { Determinar o } \\
\text { comprometimento } \\
\text { dos colaboradores } \\
\text { com a } \\
\text { organização. }\end{array}$ & $\begin{array}{c}\text { Analisar o } \\
\text { comprometimento } \\
\text { espontâneo dos } \\
\text { colaboradores } \\
\text { com o } \\
\text { desenvolvimento } \\
\text { da organização. }\end{array}$ & $\begin{array}{c}1 \text { sugestões } \\
\text { por } \\
\text { trimestre. }\end{array}$ & $\begin{array}{l}\text { Motivação } \\
\text { dos } \\
\text { colaboradores. }\end{array}$ & $\begin{array}{l}\text { Número de } \\
\text { sugestões } \\
\text { recebidas dos } \\
\text { colaboradores } \\
\text { por trimestre. }\end{array}$ \\
\hline
\end{tabular}

O ambiente de operação do processo produtivo é definido como in line. Neste ambiente, definem-se as características básicas da organização suas potencialidades e fragilidades (PALADINI, 2011). No Quadro 03 são expostos os indicadores que devem avaliar a eficiência dos processos da organização, tais como o indicador 3, 12, 13 e 14. Enquanto que, os indicadores 4 e 15 refletem o desenvolvimento da organização através do aprimoramento de suas atividades.

Quadro 03 - Indicadores ambiente in line.

\begin{tabular}{|c|c|c|c|c|c|}
\hline $\begin{array}{c}\text { Indi- } \\
\text { cador }\end{array}$ & Objetivo & Justificativa & Padrão & Elemento & Fator/Medida \\
\hline 3 & $\begin{array}{c}\text { Determinar a } \\
\text { produtividade } \\
\text { dos recursos } \\
\text { humanos. }\end{array}$ & $\begin{array}{c}\text { Reduzir o } \\
\text { consumo de } \\
\text { homens hora por } \\
\text { produto. }\end{array}$ & $\begin{array}{c}\text { Variável de } \\
\text { acordo com } \\
\text { o produto. }\end{array}$ & Produtividade & $\begin{array}{c}\text { Média de homens } \\
\text { horas por } \\
\text { produto. }\end{array}$ \\
\hline 4 & $\begin{array}{c}\text { Avaliar o } \\
\text { comprometimen- } \\
\text { to da alta direção } \\
\text { no aprimo- } \\
\text { ramento dos } \\
\text { produtos. }\end{array}$ & $\begin{array}{c}\text { Verificar o com- } \\
\text { prometimento da } \\
\text { alta direção em } \\
\text { aprimorar os pro- } \\
\text { dutos, conforme } \\
\text { solicitações do } \\
\text { mercado. }\end{array}$ & $\begin{array}{c}3 \% \text { do } \\
\text { faturamento } \\
\text { por ano. }\end{array}$ & $\begin{array}{c}\text { Desenvolvi- } \\
\text { mento de novos } \\
\text { serviços. }\end{array}$ & $\begin{array}{c}\text { \% de faturamento } \\
\text { aplicado para } \\
\text { aprimoramento } \\
\text { dos produtos por } \\
\text { ano. }\end{array}$ \\
\hline \multicolumn{1}{|c|}{ Continua... }
\end{tabular}




\begin{tabular}{|c|c|c|c|c|c|}
\hline $\begin{array}{l}\text { Indi- } \\
\text { cador }\end{array}$ & Objetivo & Justificativa & Padrão & Elemento & Fator/Medida \\
\hline 12 & $\begin{array}{c}\text { Avaliar o } \\
\text { alinhamento dos } \\
\text { processos } \\
\text { internos as } \\
\text { expectativas dos } \\
\text { consumidores. } \\
\end{array}$ & $\begin{array}{l}\text { Verificar a } \\
\text { eficácia dos } \\
\text { processos } \\
\text { internos. }\end{array}$ & $\begin{array}{l}\text { Zero de } \\
\text { ocorrência. }\end{array}$ & $\begin{array}{c}\text { Eficácia } \\
\text { organização. }\end{array}$ & $\begin{array}{l}\text { Número de } \\
\text { revisões por } \\
\text { produtos por } \\
\text { trimestre. }\end{array}$ \\
\hline 13 & $\begin{array}{c}\text { Determinar o } \\
\text { custo em } \\
\text { retrabalho dos } \\
\text { produtos. } \\
\end{array}$ & $\begin{array}{l}\text { Minimizar o custo } \\
\text { com retrabalho. }\end{array}$ & $\begin{array}{l}\text { Variável de } \\
\text { acordo com } \\
\text { o produto. }\end{array}$ & Falhas/ erros. & $\begin{array}{l}\text { Custo de } \\
\text { retrabalho de } \\
\text { produtos por } \\
\text { trimestre. }\end{array}$ \\
\hline 14 & $\begin{array}{l}\text { Determinar o } \\
\text { tempo médio de } \\
\text { resposta ao } \\
\text { cliente. }\end{array}$ & $\begin{array}{l}\text { Reduzir o tempo } \\
\text { médio de resposta } \\
\text { ao cliente. }\end{array}$ & $\begin{array}{l}\text { Variável de } \\
\text { acordo com } \\
\text { o produto. }\end{array}$ & $\begin{array}{l}\text { Comunicação } \\
\text { externa. }\end{array}$ & $\begin{array}{l}\text { Tempo médio de } \\
\text { resposta aos } \\
\text { consumidores por } \\
\text { produto por } \\
\text { trimestre } \\
\end{array}$ \\
\hline 15 & $\begin{array}{c}\text { Registrar as } \\
\text { lições aprendidas } \\
\text { e soluções para } \\
\text { aprimoramento } \\
\text { do processo de } \\
\text { gestão. }\end{array}$ & $\begin{array}{l}\text { Desenvolver } \\
\text { constantemente o } \\
\text { processo de } \\
\text { gestão da } \\
\text { organização. }\end{array}$ & $\begin{array}{l}4 \text { ações por } \\
\text { ano. }\end{array}$ & $\begin{array}{l}\text { Aprimoramento } \\
\text { dos processos. }\end{array}$ & $\begin{array}{l}\mathrm{N}^{\mathrm{o}} \text { de ações } \\
\text { realizadas a partir } \\
\text { de lições } \\
\text { aprendidas por } \\
\text { ano. }\end{array}$ \\
\hline
\end{tabular}

\section{CONSIDERAÇÕES FINAIS}

A sobrevivência de uma organização depende de sua capacidade de avaliação do ambiente interno e externo, assim como, da aptidão em transformar os objetivos estratégicos em ações. Para traduzir este pensamento foram elaborados os indicadores de desempenho segundo o modelo Balanced Scorecard. Afinal, independente das características da organização, o sucesso ou fracasso nos negócios reflete as decisões realizadas no presente.

A empresa de consultoria, em questão, tem como diferencial a personalização de processos de gestão de obras de construção civil e teve uma boa aceitação inicial. Contudo, para manter-se saudável e crescer é importante que se tenha como foco as estratégias que transformarão a visão da organização em realidade, pois suas conquistas atuais são frutos das boas escolhas realizadas no passado.

Todos os indicadores foram considerados adequados para a organização pelos seus representantes, por contemplarem aspectos financeiros, essenciais para vitalidade da empresa, por terem como meta a manutenção e crescimento em todas as perspectivas e objetivarem o desenvolvimento dos processos, recursos e atendimento aos clientes.

Portanto, estes vinte indicadores podem servir como base para medição do desempenho de suas atividades, serviços e produtos, por focarem nos eixos essenciais para toda organização. Contudo, Kaplan e Norton (2000) alertam que o sucesso do modelo em atingir melhores resultados depende principalmente do alinhamento e adesão dos recursos com as estratégias da organização durante o período de implantação.

\section{AGRADECIMENTOS}

Ao CNPq e à CAPES, pelo apoio recebido. 


\section{REFERENCIAS}

ALMAHMOUD, E. S.; DOLOI, H. K.; PANUWATWANICH, K.. Linking project health to project performance indicators: Multiple case studies of construction projects in Saudi Arabia. International Journal of Project Management, v.30, n.3, p. 296-307, jul. 2012.

AZEVEDO, R. C. Sistema computacional para coleta, armazenamento e exibição de indicadores de desempenho e produtividade da construção civil. 2009. 296 f. Dissertação (Mestrado) - Programa de Pós Graduação em Engenharia Civil. Universidade Federal de Santa Catarina, Florianópolis, 2009.

DAVE, B.; KOSKELA, L. Collaborative knowledge management: A construction case study. Automation in Construction, v.18, p. 894-902, mar. 2009.

GHOSH, S.; MUKHERJEE, S. Measurement of corporate performance through balanced scorecard: An overview. Vidyasagar University Journal of Commerce, n.11, p. 60-70, 2006.

GRIGOROUDIS, E.; ORFANOUDAKI, E.; ZOPOUNIDIS, C. Strategic performance measurement in a healthcare organisation: A multiple criteria approach based on balanced scorecard. Omega, v.40, p. 104-119, jan. 2012.

GUZI, D. Avaliação da cultura organizacional na gestão de empresas: indústria da construção civil. 2011. 181 f. Dissertação (Mestrado) - Programa de Pós-graduação em Engenharia Civil, Universidade Federal de Santa Catarina, Florianópolis, 2011.

KAPLAN, R.S.; NORTON, D.P. Organização orientada para a estratégia: Como as empresas que adotam o Balanced Scorecard prosperam no novo ambiente de negócios. 14. ed. Rio de Janeiro: Elsevier, 2000.

KURESKI, R. Produto interno bruto, emprego e renda do macrossetor da construção civil paranaense em 2006. Ambiente Construído, Porto Alegre, v. 11, n. 3, p. 131-142, jul./set. 2011.

HERNANDES, F. S. Indicadores do processo produtivo na tomada de decisão estratégica dos dirigentes de pequenas empresas construtoras. 2008. 241 f. Tese (Doutorado) Programa de Pós-graduação em Engenharia Civil, Universidade Federal de Santa Catarina, Florianópolis, 2008.

PALADINI, E.P. Avaliação estratégica da qualidade. 2. ed. São Paulo: Atlas, 2011.

RAJESHA, R, et al. Sustainable development of manufacturing and services generic balanced scorecard framework for third party logistics service provider. International Journal of Production Economics, v. 140, p. 269-282, fev. 2012.

ZORZI, A.; ENSSLIN, L. Gestão do setor de contabilidade de uma entidade fechada de previdência complementar com base nas ferramentas BSC MCDA-C. Revista Contemporânea de Contabilidade, v. 4, n. 7, p. 101-124, jan./jun. 2007. 